Sociologias, Porto Alegre, ano 17, no 40, set/dez 2015, p. 416-425

\title{
Felicidad: lecciones de una nueva ciencia
}

LAYARD, Richard. Felicidade: lições de uma nova ciência. Rio de Janeiro: Best Seller, 2008.

\section{FERNANDO TULA MOLINA"}

\section{Resumen}

Este libro busca comprender la paradoja por la cual cuando las sociedades occidentales se volvieron más ricas, sus integrantes no se volvieron más felices La hipótesis es que el individualismo falló: no aumentó la felicidad de los individuos; si realmente deseamos ser felices necesitamos de un concepto de bien común al cual contribuir... exige cuidado del otro, tanto cuanto de nosotros mismos. El marco filosófico de esta reflexión lo proporciona el pensamiento de Jeremy Bentham según el cual la mejor política pública es la que produce más felicidad.

Palabras clave: Individualismo. Bien común. Richard Layard. Jeremy Bentham.

\section{Happiness: Lessons from a new science}

\section{Abstract}

This book tries to clear why west societies do not get happier while turning richer. The hypothesis is that individualism failed. Its main statement suggests that if we really want happiness we need a concept of common good to contribute: it requires self-care and care of the other. The philosophy of Jeremy Bentham, which

\footnotetext{
$\overline{{ }^{*} \text { Universidade Nacional de Quilmes, Buenos Aires (Argentina) }}$
} 
states that the best policy is that which produces more happiness, offers the frame for all Layard assessments.

Keywords: Individualism. Common good. Richard Layard. Jeremy Bentham.

Este libro busca comprender la paradoja por la cual, cuando las sociedades occidentales se volvieron más ricas, sus integrantes no se volvieron más felices; mientras la renta se duplicó en los últimos 50 años, la felicidad no aumentó. Esto es válido tanto para EEUU, como para Gran Bretaña y Japón. La hipótesis es que el individualismo falló: no aumentó la felicidad de los individuos; si realmente deseamos ser felices necesitamos de un concepto de bien común al cual contribuir... exige cuidado del otro, tanto cuanto de nosotros mismos (p. 20). El marco filosófico de esta reflexión lo proporciona el pensamiento de Jeremy Bentham según el cual la mejor política pública es la que produce más felicidad. El libro se estructura en dos partes, la primera identifica el problema y la segunda propone líneas de acción.

\section{El problema}

¿Cómo mantener la confianza cuando la sociedad está cada vez más inestable y anónima? Layard defiende que somos inherentemente sociales y que nuestra felicidad depende sobre todo de nuestra relación con otros; por este motivo tenemos que desarrollar políticas públicas que tenga en cuenta ese factor de relación. A nivel personal, el mensaje del libro toma forma de advertencia; si bien los humanos conquistaron la naturaleza todavía les falta conquistarse a sí mismos... El desafío de generar felicidad, es "aún más difícil que el de generar riqueza en el sentido tradicional (p. 24). Y si nos preguntamos iqué es la felicidad?, su respuesta apunta a sentirse bien, aprovechar la vida y desear que esa sensación se 
mantenga (p. 29). Es interesante cómo Layard muestra que existe una conexión directa entre actividad cerebral y humor, y entre humor y mejora del sistema inmunológico. Por el contrario, no existe tal conexión entre felicidad y aumento de renta. En los países con más de 20000 dólares per cápita, la renta adicional no está asociada a mayor felicidad. La renta extra es realmente valiosa cuando saca a las personas de la pobreza extrema ( $p$. 51). Lo que resulta preocupante es que con el aumento de renta lo que aumentó fue la depresión y no la felicidad; la tendencia a la depresión, al alcoholismo y al crimen son indicaciones concretas de que la infelicidad aumentó rápidamente en el período post-guerra; 6\% en EEUU tiene una gran depresión por año (p. 54) ¿Por qué no se es feliz siendo rico? En su opinión el crecimiento económico no aumenta la felicidad porque en la misma medida en que se eleva, también aumenta le criterio con el que se la juzga (p. 60) Por otra parte, la renta no es sólo un medio de comprar, sino también de compararse con los otros; de aquí la importancia de la renta relativa: la mayoría prefiere ser más pobres si su posición relativa en su entorno mejora. El punto es que nos acostumbramos a nuestros bienes materiales; debemos tener esto presente para no invertir demasiado en adquirirlos a costa de nuestro tiempo libre (p. 68). A diferencia de EEUU, los países europeos decidieron trabajar progresivamente menos a medida que la renta aumentó. De modo general, puede decirse que los países ganan en felicidad a medida en que distribuyen mejor su renta; y esto fundamentalmente porque cuando el dinero va de ricos a pobres, la persona pobre gana más felicidad de lo que la rica pierde (p. 71).

Layard reconoce siete grandes factores que influyen en la felicidad; estos son: relaciones familiares, situación financiera, trabajo, comunidad y amigos, libertad personal y valores personales; salvo por la renta, todos hablan de relaciones. La calidad y la estabilidad de las relaciones importa más que su forma: necesitamos de otras personas y de que otros 
necesiten de nosotros; cada vez más las investigaciones confirman la máxima importancia del amor (p. 87). Un buen test de felicidad consiste en saber si Ud. siente que el mundo es un lugar amistoso; las respuestas varían: 5\% Brasil, 64\% Noruega (p. 89). Lo cierto es que la guerra resulta el mayor factor de infelicidad: cien millones de personas murieron en el siglo XX por su causa.

Para comparar la felicidad de 50 países en 4 años diferentes Layard utiliza el World Values Survey, y llega a la conclusión de que seis factores, de los siete grandes, explican la variación del 80\% de la felicidad (p. 91). Aún de modo más general, puede decirse que las personas que se preocupan por otros son en media más felices de las que se preocupan por sí mismas. En este sentido, lo que importan no es lo que la vida le ofrece, sino lo que uno ofrece a la vida. Resulta claro que tenemos elecciones frente a nuestros objetivos y que el problema consiste en elegir bien. Al respecto, cita las palabras de Lord Keynes: Para quienes sudan por ganar el pan de cada día, el tiempo libre es un dulce muy deseado, hasta que lo tienen (p. 95); en parte por ello es que la mayor felicidad proviene de concentrarse en un objetivo fuera de nosotros mismos. Ahora bien, ¿qué es lo que está funcionando mal? Layard apunta a varios factores; uno de ellos es el deterioro de los lazos sociales a partir de la vida mediática. En 1998, el rey de Bután anunció que el objetivo de su nación sería la Felicitad Interna Bruta; al año siguiente, tomó la decisión fatal de permitir la TV en su país (p. 99); todos notaron aumento de criminalidad, desintegración familiar y consumo de drogas, así como aumento de la violencia en las escuelas. También la TV disminuye la satisfacción de las cosas que tenemos. Se estima que 1 hs. Más de TV por semana hace gastar 4 dólares más para tener lo que otros tienen (p. 112). En EEUU, cada nueva generación comienza su vida adulta en un nivel de confianza más bajo que el de las generaciones anteriores. Otro factor consiste en la mayor inserción de las mujeres en el mundo la- 
boral, lo cual las deja sin tiempo. La falta de tiempo es una de las grandes fuentes de tensión interna en la vida familiar (p. 211).

En cuando a los valores morales y espirituales, Layard observa que ante el debilitamiento del cristianismo y de la solidaridad social, sólo quedan dos ideas dominantes: la selección natural de Darwin y la mano invisible de Adam Smith; es necesario ofrecer una alternativa (p. 115) ¿Podemos perseguir un objetivo común? Si bien muchas de las interacciones humanas son de suma nula, una gran parte - la mejor - consiste en interacciones que aumentan nuestro bienestar general. La cooperación permite ventajas para ambas partes... sobrevivimos porque nuestros genes nos dan la capacidad de cooperar. En el centro de la moralidad está una idea de justicia basada en un profundo sentido de reciprocidad para con las personas; en casi todas las decisiones humanas la emoción es un componente necesario: algo más que el cálculo de beneficios a largo plazo y a la presión por la gratificación inmediata (p. 125). A pesar de nuestro constante egoísmo, también hay un trazo de bondad que nos vuelve capaces de cooperar en busca del bien común; a veces, dar proporciona más satisfacción que recibir... el buen comportamiento suscita también buen comportamiento en otros (p. 130). Hobbes estaba errado al sostener que es sólo el miedo al castigo el que conduce a la cooperación humana.

\section{¿Qué puede hacerse?}

Según Bentham, una sociedad es buena en la medida en que sus ciudadanos son felices, por lo que una ley es buena si aumenta la felicidad y disminuye el sufrimiento. Cuando los políticos pragmáticos afirman que están haciendo lo que funciona, podemos preguntarnos: lo que funciona ipara qué fin? Los mencionados siete grandes factores son análogos a las capacidades personales que Amartya Sen propone como objetivo de 
las políticas públicas (p. 139). Por lo tanto, si queremos evaluar la calidad de vida, debemos basarnos en cómo se sienten las personas; en esto debe consistir la idea de bien social. La sociedad feliz debe construirse sobre dos bases: (i) mayor nivel de solidaridad, (ii) principios morales más sólidos de imparcialidad. Teniendo en cuenta la felicidad relativa que aporta el dinero, el principio de felicidad mayor está a favor de los pobres y no apoyaría la reducción de impuestos en EEUU (p. 147). Según tal principio, la única cosa que importa son los sentimientos de todos los involucrados; si una política produce más felicidad que otra, es mejor.

Ya que está comenzando a ser posible medir el aumento de felicidad de las personas, es el momento para un serio debate sobre los pesos a darse a los diversos cambios de felicidad (p. 149). Este debate público debería guiarse por el principio de felicidad mayor, el cual: (i) ayuda a encontrar las reglas, (ii) ayuda a escoger la acción cuando las reglas están en conflicto. Se trata de un principio universal que valoriza la felicidad de todos por igual; quienes actúan correctamente amplían la felicidad. Lo que está errado en la economía es su teoría de la naturaleza humana (basada en un anticuado behaviorismo) (p. 155). Necesitamos medir la felicidad media de la población; en lugar de ello, los gobiernos se concentran en el PBI (donde el dinero todo lo equipara), y ello a pesar de que la mayoría de los economistas reconoce fallas en el PBI como medida de bienestar ( $p$. 163). Debe, consiguientemente, reformarse la economía para acompañar la nueva psicología del bienestar. ¿Qué criterio utilizar para valorizar las ganancias de los pobres frente a las pérdidas de los ricos? Esta respuesta fue teóricamente respondida por un grupo de economistas brillantes, inclusive los ganadores del Premio Nobel James Meade, James Mirrlees y Amartya Sen. Ellos parten del principio de que 1 dólar extra da más felicidad a los pobres que a los ricos. Por esto, debemos tasar a los ricos en beneficio de los pobres. Debe tenerse en cuenta, además, que la redistribución más 
igualitaria del PBI, lo hace caer; por lo tanto, el objetivo último no puede ser el aumento del PBI (p. 165). Los economistas se concentran en las recompensas financieras externas, ignorando el papel de la recompensa interna de un trabajo bien hecho. El aumento de los incentivos financieros disminuye los incentivos internos de las personas para dar lo mejor de sí (p. 188). Un ámbito de trabajo mejor supone enseñar a nuestros hijos que el objetivo no es ganar la delantera, sino un trabajo bien hecho (p. 189). Por otra parte, la felicidad de una sociedad tiende a aumentar en la medida en que las personas se preocupan unas con otras; se vuelve necesario una revolución académica para entender las causas de la felicidad.

Por otra parte, debe reconocerse que la lucha por la renta relativa, involucra un gran desgaste social y un nulo aumento de ganancia social. También deben fijarse impuestos a la polución guiados por la búsqueda de un equilibrio entre trabajo y vida, tasando tanto las emisiones nocivas, como el trabajo excesivo (p. 181). En este sentido, la mayoría de los europeos está feliz con su jornada laboral más corta, a pesar de la crítica de los economistas americanos. Este proyecto requiere acompañarse de una fuerte regulación de la publicidad, la cual representa un desperdicio extraordinario, donde los niños quedan con la idea que de que deben gastar mucho para ser ellos mismos (p. 190). Esto ya ha comenzado en Suecia donde se prohíbe propaganda para menores de 12 años. Es una falacia capitalista la afirmación de que menos publicidad es causa de desempleo; lo que causa es un deseo de las personas de trabajar menos y comprar menos. Somos entrenados demasiado tiempo para esforzarnos y demasiado poco para divertirnos (L. Keynes) (p. 194).

¿Podemos darnos el lujo de sentirnos más seguros? Las personas desean seguridad en al menos cinco primeros de los siete grandes: renta, trabajo, familia, comunidad y salud. Por el contrario, Reagan, Thatcher y Bush criticaron la seguridad que valoran las personas como peligrosa. Con relación al trabajo 
todos deberían poder dejar sus trabajos en la medida de considerarlos excesivos; pero también a todos habría que ofrecerles la posibilidad de participar de un sistema libre de ansiedades (p. 202). No se puede reducir el desempleo a través de generar demanda agregada por la producción de un país; ello sólo genera inflación. Por el contrario, la búsqueda del pleno empleo debe hacerse por la vía del pago regional ligado a la productividad regional; esto implica salarios descentralizados (p. 206). La flexibilidad laboral no es un mantra sensato si deseamos pleno empleo y una vida profesional de buena calidad; la movilidad geográfica que favorecen los economistas aumenta la desintegración familiar y la criminalidad (p. 211).

¿Puede la mente controlar el humor? Ha quedado claro que la meditación hace bien tanto al espíritu como al cuerpo, en tanto mejora inmunológica. Sabemos que el sólo acto de sonreír - clave en el budismo - fisiológicamente mejora las hormonas de una persona. Layard se refiere también aquí a toda la tradición mística donde el objetivo no es la autorrealización, sino una relación armoniosa con el entorno (p. 222); ser agradecidos se vuelve - como en San Ignacio una condición esencial para la felicidad y el servicio al prójimo, un servicio a la divinidad (p. 223). Por el contrario, la depresión involucra un círculo vicioso de pensamientos que son auto-destructivos y auto-reforzadores. Un punto importante para Layard es que la felicidad depende de nuestras actitudes y que éstas pueden ser aprendidas y practicadas (p. 231). En consecuencia, también explora las vías de la terapia cognitiva y de la psicología positiva. La psicología positiva lleva a concentrarnos en las áreas de la vida en las que podemos florecer. En tal sentido, la flexibilidad es la verdadera enemiga de la felicidad (p. 229).

Y, por último, Layard se pregunta si realmente ayudan las drogas. En su opinión resulta claro que las drogas psiquiátricas cambiaron la vida de millones de personas. La clorpsomazina reduce el delirio de los esquizofrénicos y activa a las personas que se retiraron a su interior; el litio ayuda 
a estabilizar el humor en el trastorno bipolar (sea tanto de la fase de la depresión como de la manía. Ya en 1975, el 15\% de los americanos tomaba diazepam (Valium), o algo similar (p. 244). En conclusión, si bien ninguna es perfecta, y no funcionan en todos los casos y pueden tener efectos desagradables, es casi inevitable que, a medida que las drogas mejoren, las personas las usen para mejorar su estado mental (p. 249).

La conclusión del libro es que la felicidad es una dimensión objetiva de nuestra experiencia y que efectivamente puede ser medida: podemos preguntar a las personas cómo se sienten, podemos pedir una evaluación independiente por medio de terceros y también podemos medir la actividad eléctrica en la parte relevante del cerebro. En definitiva, para Layard, estamos programados para buscar la felicidad... por lo que todo comportamiento moral hace a una persona sentirse mejor (p. 254) y que, por lo tanto, la mejor sociedad es la más feliz. Sin embargo, la sociedad no tenderá a ser más feliz, si las personas no concuerdan en que esto es lo que quieren. La sociedad moderna necesita desesperadamente de un concepto de bien común en torno del cual unir los esfuerzos de sus miembros. La fuente de la felicidad está en nuestra sociabilidad. En tanto seres sociales queremos confiar unos en otros. Paralelamente las personas también están profundamente ligadas al status quo. El objetivo de una política pública debe ser la felicidad, no el dinamismo (p. 259). El ser humano también se acostumbra a su renta lo cual disminuye su sensación de satisfacción y felicidad; la renta es viciante. Por lo tanto, como a mayoría no prevé los efectos viciadores de la renta y de los gastos, la tasación tiene una vez más un papel útil: nos desestimula a trabajar demasiado, y a correr en una estera hedonista que nos hace avanzar menos en la dirección de la felicidad de lo que esperábamos (p. 260). Y esto porque, en realidad, la felicidad depende tanto de la vida interior cuanto de las circunstancias externas. 
¿Qué hacer? Debemos monitorear atentamente el aumento de la felicidad en nuestros países, tanto cuanto aumentamos el aumento de la renta; debemos repensar nuestra actitud en relación a las cuestiones comunes, gastar más ayudando a los pobres y prohibir la propaganda comercial dirigida a menores para evitar la escalada constante de deseos. Finalmente, y tal vez lo más importante, precisamos de una mejor educación, para un mundo mejor, e incluso de educación moral, con un objetivo básico: la conciencia de un propósito global más amplio que el propio yo (p. 266).

Fernando Tula Molina é Professor do Departamento de Ciências Sociais da Universidade Nacional de Quilmes e investigador Adjunto do Conicet. $>$ ftulamolina@gmail.com

Recebido em: 05/11/2014

Aceite Final: 15/12/2014 